epiphany

Journal of the Faculty of Arts and Social Sciences

International University of Sarajevo

ISSN 1840-3719 / No. 3 - Special Issue: Identity

Fall 2009

\title{
One Name, Several (Wo)Men: \\ Cultural Categories of Identity in Virginia Woolf's Orlando: A Biography
}

\author{
Aline Sanfelici \\ Federal University of Santa Catarina
}

This essay elaborates on the cultural constructs depicted in the characterization of Orlando's identity in Virginia Woolf's novel, Orlando: $A$ Biography. The analysis is conducted through close reading of selected passages in light of the intersections between nation, class, and gender as regards Orlando's characterization. The results of the analysis show that the novel seems to challenge and criticize cultural constructs that cause social hierarchies, however, results also show that the novel's subtext ends up reinforcing such hierarchies, and must therefore be criticized on this aspect.

To begin the discussion, I must first elaborate on the concept of intersectionality. In "Mapping the Margins: Intersectionality, Identity Politics, and Violence Against Women of Color," Kimberlé Crenshaw asserts that intersectionality points to the relations between several grounds of identities, as they relate to one another, often in prejudicial and oppressive ways. Crenshaw claims that identity politics frequently erase the differences between these grounds, ignoring, in consequence, the fact that oppressions are caused not because of one dimension solely: for example, "[i]n the context of violence against women, this elision of difference is problematic, fundamentally because the violence that many women experience is often shaped by other dimensions of their identities, such as race and class." In short, then, intersectionality signals how inter-related factors, once 
combined, can constitute multiple levels of discrimination. Hence, a reading of intersectionality is important to demystify such discourses of discrimination.

Further, this notion of intersectionality points to how subjects are constituted by various-often conflicting-positions, and consequently points to the permanent calling into question of pre-established categories, whether they are closed or open labels of identity. This approach recalls that of Judith Butler who argues, in Gender Trouble, that it is not correct to conceive "a category of 'women' that simply needs to be filled in with various components of race, class, age, ethnicity, and sexuality in order to become complete. The assumption of its essential incompleteness permits that category to serve as a permanently available site of contested meanings" (15, my italics). In this study, such a perspective of intersectionality allows for an analysis of how Orlando's characterization is constituted through the very interruption of identity categories. In what follows, I focus on the categories of nation, class, and gender.

\section{Nation}

Following Werner Sollors (1990), by nation I mean a group of people who are born and live in a particular country (territoriality), and have a political and economic unit, as well as a shared history and culture (290). Further, following Lydia Liu (1994), nation is understood as "a historical construct rather than a manifestation of some unchanging essence" (37, my italics), which implies that nations, by being arbitrarily instituted and "invented," can intervene in their own historical trajectories. Nation, for Liu, is also culturally constructed, through binaries like East/West and First World/Third World. Finally, referring to Timothy Brennan's ideas (1990), nation is "historically determined" (45), but also refers to a current usage of being a state, a usage that is built for political purposes; and to "something more ancient and nebulous-the 'natio'-a local community, domicile, 
family, condition of belonging" (45). In addition, Brennan proposes that since nations are to some extent invented, or forged by culture and history, then they are simply artificial, or mythical (47). In this sense, the component of nationality within Orlando's characterization should be considered from the perspective that nations are "imaginary[1] constructs that depend for their existence on an apparatus of cultural fictions" (49).

In Woolf's novel, the "imaginary community" that Orlando seems, in a first moment, proud to belong to is a nation of great men who did remarkable deeds. As will be indicated in the following excerpt, Orlando thinks only of men, not of women. This fact suggests a "masculinization" of the nation, which takes place probably because Orlando is living in the seventeenth century, and A. G. Eyre (1971) tells that up to the eighteenth century, "gentlemen were accustomed to settle their quarrels with the sword" (111), and that "[t]he early Victorian father... had fixed ideas, especially about women. A woman's place was in the home... Even in the home, her interests and conversation were strictly controlled" (141). What I want to emphasize is that Orlando's nation, in this period, is masculinized" due to the roles given to men and women, since these roles implied women to be passive and obedient, with restricted opportunities to contribute to their nations:

[s]tanding upright in the solitude of his room, he vowed that he would be the first poet of his race[2] and bring immortal luster upon his name. He said (reciting the names and exploits of his ancestors) that Sir Boris had fought and killed the Paynim; Sir Gawain, the Turk; Sir Miles, the Pole; Sir Andrew, the Frank; Sir Richard, the Austrian; Sir Jordan, the Frenchman; and Sir Herbert, the Spaniard. (57)

This feeling of pride would lead Orlando to wish to accomplish, though through literature and not physical battles, a remarkable deed of his own, and like the cited men, to contribute to enriching his nation. The masculinization of nation 
appears not just in the mentioning of only men by Orlando, but also in the idea that one can contribute to enrich the nation through literature and physical battles only. As mentioned, physical battles were men's job. Literature, too, was restricted to men. According to Sandra Gilbert and Susan Gubar (1994), the literary pen is frequently understood as a sword of battle in the discussions of gender and imperialism in literature. It is a "metaphorical penis," that is, the writer is implied to be constituted by the anatomy of the male sex. In other words, Orlando would contribute to the nation through literature, because he, as a young man in this moment of the story, is able to do so.[3] On this account, I point out an intersection between nation and gender within character construction: the gendering of the nation as male is intersectional in that it discriminates and excludes all who, for not being biologically male, cannot take part in this nation in the same ways as those who are male (the "great men" who can enrich the nation). Furthermore, the monarchic political system around which Orlando's nation is organized is also gendered male: "the odious Parliament days were over and there was now a male Crown in England again" (74).

Orlando is then characterized as being devoted to his nation, as can be seen in the sequence: "at this stage of Orlando's career, [he] played a most important part in the public life of his country" (84), since he "was English root and fibre" (85). The choice of words used in the narrative suggests a "masculinized" nation, once more: the expression "public life" indicates that the role played by Orlando could only be played by a man, since public life can be seen as opposite to domestic life, which was relegated to women, like I exposed before. Also, the omniscient narrator's expression "root and fibre" refers to a stereotypical attribute to men, who were supposed to be strong and brave (and therefore were supposed to be the ones who could defend the interests of the nation). On account of the referred stereotypical 
attribute to men, I recall Alan Sinfield's claim that masculinity and femininity, the way men and women should behave and be characterized, are "ideological constructs" that have "no essential relation" to the variable attributes of men and women which are not determined by rules (26). By recalling this argument in contrast to Orlando's characterization above, I suggest that the narrator, here, reinforces ideological, cultural categories of gender through the nation's "masculinization," and therefore perpetuates a limiting and problematic conception of men and women identity's legibility.

Later in the story, Orlando awakens as a woman in terms of anatomical features (such event is more thoroughly discussed in section 3 above), and moves to living in the company of gypsies. If nation is an "imagined community" and implies the condition of belonging (Brennan's term), Orlando seems to belong to the gypsy's nation, now. We should observe, though, that this nation, differently from Orlando's previous one in England and Constantinople under a monarchic system, is not defined by geopolitical, administrative and institutional fixed boundaries. Rather, the gypsy's nation is determined by openness to the non-fixity of the subjects that comprise such nation, and therefore openness to the boundaries of the community.

In the process of belonging to this nation, Orlando is only accepted by the gypsies if she takes a stand against her class privileges (100); that is, the gypsies accept Orlando's lineage and past origins, but reject her classist ideology. Orlando then joins the community acting as a sojourner, for she is aware that she can return home if any difficulty might arise. Considering that non-fixity is only possible with change, and Orlando resists changing her classist privileges and ideology, the gypsies end up rejecting and even planning to kill her (106). In short, her belonging among the gypsies' nation is betrayed by her classist values and the privilege to leave the community anytime: she merely visits rather than crosses over to the 
gypsy nation, due to their incompatible conceptions of class.

We should notice, however, that before being rejected by the gypsies, Orlando does try to take part in their nation, engaging in their activities: she "milked the goats; she collected brushwood" and "stripped vines; she trod the grape" (100). Also, Orlando respects and engages in this culture, by dressing like them, for instance. Furthermore, through the activities I mentioned the character performs, we can see that Orlando experiences being an active member of the nation. Bearing in mind that the character is in this moment a woman (in anatomical terms), it is important to observe that in the gypsy culture, adults have different roles according to their genders, but both men and women are assigned active roles to contribute to the functioning of the nation. In other words, Orlando now is a woman actively contributing within a nation in which gender categories are understood differently, compared to the other community she experienced before, in London, in which nation was portrayed as "masculinized."

In this context, intersection becomes central in the way Orlando is characterized in crossing the boundaries of nation and class. As I argued before, while experiencing life among the gypsies, Orlando refuses to abandon certain classist values, and is therefore rejected by the gypsies. As she realizes how different their values are, she decides to abandon the gypsies, and returns to England. This attitude reinforces the idea that Orlando acts as a tourist among the gypsies, for she leaves them when difficulties regarding conciliation arise: "'Four hundred and seventy-six bedrooms mean nothing to them,' sighed Orlando. 'She prefers a sunset to a flock of goats,' said the gypsies" (105). So Orlando reinforces the intersection between nation and class, and then returns to a nation that was argued before to be gendered biased. In other words, what makes this characterization intersectional, in Crenshaw's sense, is precisely the fact that 
Orlando is a subject constituted by several positions that often conflict with each other; specifically, a "tourist" who lives as a gypsy but still carries classist values that differ sharply from the gypsy's values. So Orlando's characterization is intersectional for it interrupts identity categories of nation and class, by disturbing closed labels associated with these grounds of identity.

\section{Class}

According to James H. Kavanagh (1990), class involves the political, economic and cultural elements in the relationships among societies. More specifically, drawing on E. D. Hirsch, Joseph F. Kett, and James Trefil (2002), class "usually implies a social and economic hierarchy, in which those of higher class standing have greater status, privilege, prestige, and authority." In addition, Hirsch, Kett, and Trefil signal the importance of class consciousness, which is described as one's identification with members of the same class linked to a realizing of the way this class relates to other classes.

Orlando's characterization shows him/her at first as a nobleman who participates in a rich and privileged group in society. Orlando spends a lot of money reconstructing his house and offering parties. These facts indicate that his characterization, in this moment and as conveyed by the narrative, is of comfort and satisfaction with the class he lives in. As a matter of fact, discussing the context of England in the Elizabethan period, Clayton Roberts and David Roberts (1991) report that reconstructed houses were used to "proclaim the ostentation, the extravagance, the self-consciousness, and even the vulgarity of a newly enriched landed class" (313), and that this self-consciousness was also noticed in the "willingness to offer hospitality" (313, my italics).

Concerning the wealth of Orlando's family, we learn in the very beginning of the story that "[h]is fathers had been noble since they had been at all. They came 
out of the northern mists wearing coronets on their heads" (11). The tone of the narrative implies that Orlando chooses to vary the identity of class he is supposed to have for belonging to a noble, wealthy family: Orlando's father wore coronets, but Orlando does not necessarily and naturally need to do the same. Indeed, Orlando enjoys the company of lettered people conceived as "low company" (20), identifies with and acts like them, and therefore shows that it is not natural to be noble. Thus, Orlando's characterization here challenges the liberal assumption that one's identity is stable and natural, and should therefore be celebrated on this aspect.

Further into the family's means, it can be observed that the narrator does not indicate the origin of such wealth. This fact is crucial, because the family has not been noble forever, as the narrator characterizes it; obviously there is an origin to such wealth. It seems, at first glance, that being noble is essential, natural, and timeless to Orlando's family, because they "had been noble since they had been at all." This is a dehistoricized characterization that quickly hides the fact that the family's wealth was originated due to historically asymmetrical power relations. With a dehistoricized perspective, Orlando's characterization here does not engage social historical conflicts and ends up mystifying nobleness and a consequent imperialist privilege of Orlando and his family in relation to the gypsies. In this case, it seems that there are great differences between these two groups - and this is precisely what the narrator attempts to suggest. However, if we engage in a historicized perspective that does not assimilate given elements such as wealth as timeless and unquestionable, we will find that the origin of the noble's wealth is similar to the origin of the gypsies' (smaller) wealth, that is, both are originated due to hierarchies and relations of power that either privilege or oppress one.

Moreover, what the gypsies own is generally considered robbery, but the nobles are so much wealthier exactly because of robbery too, through manipulation, 
hierarchy, and privilege. In other words, while the narrator struggles to characterize Orlando as so different from the gypsies, they are actually similar in this sense. Hence, Orlando: A Biography presents an imperialist and assimilationist subtext that dehistoricizes conflicts and reinforces the oppressions that cause great differences within nations, classes, and even genders. It is thus possible to see a contradiction in the novel, as it appears to be a transgressive text but, at the same time, hides such a normatizing subtext.

Later, we learn that Orlando is someone "to whom fortune had given every gift - plate, linen, houses, men-servants, carpets, beds in profusion" (52). On this note I want to stress the fact that the narrator here offers a positioning in which materiality matters. The narrator considers as "gifts" material elements such as fine fabrics and numerous (and certainly more than the necessary) habitations. In valuing this kind of life and the materiality it involves, the narrator probably disapproves Orlando's experiences in other less wealthy classes. My point is that the narrator is in conflict: before, with the gypsies, the narrator challenged the assumption of a fixed class to be occupied, and now he/she seems to be disapproving the experiencing in other classes like the low lettered people. Further, if materiality matters, again the novel's subtext conveys imperialism and classist values.

As the story develops, we learn that Orlando's characterization within class can be seen as variable; that is, not only does the character shift between classes, but also the positioning within classes shifts. For instance, in his affair with the Russian princess Sasha, he is both proud of his situation and tries to escape from this life. Orlando's pride can be seen when he tells Sasha about the history of his family, talking about their privileges with "an orgulous credulity" (33). On the other hand, his contrary positioning of trying to escape his noble background can be noticed every time Orlando and are "seen to slip under the silken rope, which railed 
off the Royal enclosure from the public part of the river and to disappear among the crowd of common people" (30). My point is that at times the character is portrayed as comfortable and satisfied with his positioning within a wealthy class, and at other times he does not live his noble identity and denies it, exchanging it for a new one. Still, in this latter case Orlando can move within classes keeping the privilege of returning any time. So, again, there is an elitist, imperialist subtext implied in the novel.

Observing now Orlando's attempts at being a writer, such desire, attached to his education and position as a noble (wo)man, at a certain moment in the story, make the character face the fact that his/her noble position offers not only privileges but also limitations or barriers to surpass. This is parenthetically observed by the omniscient narrator in the following passage: "'[n]ot a Nobleman; not one of us,' said Orlando (which he would not have said aloud, for he was the most courteous of gentlemen; but it shows what an effect noble birth has upon the mind and incidentally how difficult it is for a nobleman to be a writer)" (56). The narrator's comment about the effects of belonging to a certain class points to a reality faced by Orlando in the beginning of his life (for the character lives for three centuries). However, Orlando's insistence on writing the poem "The Oak Tree" and publishing it at the end of the novel, signals that the characterization of Orlando within class is convenient: it is of both belonging to a specific group and detaching oneself from it, in order to pursue the goals that are considered permissible in each group.

Therefore, Orlando varies classes and blurs the limits of the classes he/she takes part in, but from a liberal standpoint. What I mean is that Orlando takes part in different classes so that he/she finds room to write, in one class, when he/she needs to write; and finds room to publish the writing, moving to another class, when he/she needs support to do so. In other words, again Orlando has the privilege to 
shift within classes according to his/her own needs-and not everybody has such privilege. To illustrate this, it should be noted that parts of "The Oak Tree" are written while the character lives among the gypsy community, but the poem is published when the character participates again in the noble class.

In the following excerpt, the omniscient narrator reflects the character's selfcategorization by occupation, rather than by class: "[e]agerly recalling these and other instances of his unfitness for the life of society... proved that he himself belonged to the sacred race rather than to the noble-was by birth a writer, rather than an aristocrat-possessed him" (58, my emphasis). Here, there is the disturbance of the issue of race: the narrator equates being noble with being an aristocrat, whereas being a writer is equated with belonging to a sacred race "by birth." Hence, there is an intersection between class and race here, which causes a hesitation between received and constructed identitarian categories, each of which is simultaneously set and rejected. After all, being a published writer seems to be related to class, as explored earlier, but in the excerpt just mentioned, it seems to be related to race. In Crenshaw's sense, then, this intersectionality subtracts the radical issue of class within writing, that is, the writing profession is no longer marked by matters of social position. This slipperiness and deferral indicate that the novel politicizes identitarian categories used in Orlando's characterization by the omniscient narrator, as these categories are destabilized and not fixed.

In short, considering Orlando's general characterization within class, the description of Orlando's transit between richer and poorer classes reveals that such characterization is unstable, but this instability is made possible by the very class privilege Orlando is taken for granted to have transgressed or transcended.

\section{Gender}

At the time the novel was written there was no distinction between gender 
and sex. Woolf and her generation did not have clear theoretical distinctions between gender, sex, and sexuality, and recent theorists have sought to clarify these terms. So, in the following discussion of Orlando's characterization within gender, some of the passages quoted should be understood taking into account this earlier context of scarce theorization about the topic.

In the beginning of the novel, Orlando is described as a man in definite terms, yet ambiguous regarding anatomy and/or behavior, based on genitalia: "[h]efor there could be no doubt of his sex, though the fashion of the time did something to disguise it (11)". In terms of behavior, there are passages that insinuate that Orlando behaves as men are expected to behave at the time: Orlando gets involved with ladies, writes poems about them and has his name related to their names in marriage. Indeed, "Orlando's taste was broad; he was no lover of garden flowers only; the wild and the weeds even had always a fascination for him" (20). In short, the initial portrayal of Orlando suggests a "correspondence" between his behavior and his genitalia, through his heterosexuality-a correspondence in terms of the cultural constructions and expectations of untroubled gender and sex.

However, in the sequence, the narrator makes us pause and see how the character behaves (and feels) in variable ways about gender in terms of sexual attraction:

when [Orlando] beheld, coming from the pavilion of the Muscovite Embassy, a figure, which, whether boy's or woman's, for the loose tunic and trousers of the Russian fashion served to disguise the sex, filled [Orlando] with the highest curiosity. The person, whatever the name or sex, was about middle height, very slenderly fashioned, and dressed entirely in oyster-coloured velvet, trimmed with some unfamiliar greenish-coloured fur. But these details were obscured by the extraordinary seductiveness which issued from the whole person (26, my italics). 
In this passage, clothing is a form of contribution to make visible and clear gender (artificial) constructs. Orlando is seduced by the person, "whatever the name or sex." However, he feels estrangement of sex/gender, in case the person is a man: "[w]hen the boy, for alas, a boy it must be... swept almost on tiptoe past him, Orlando was ready to tear his hair with vexation that the person was of his own sex, and thus all embraces were out of the question" (26, my italics). Elizabethan social rules could prevent Orlando from certain acts, as he is a man engaged to a woman and should not be seen flirting with another man.

The development of this moment is: "[b]ut the skater came closer. Legs, hands, carriage, were a boy's, but no boy ever had a mouth like that; no boy had those breasts; no boy had eyes which looked as if they had been fished from the bottom of the sea" (26-7). Here Orlando does not know who the other person is, but cannot help feeling attracted to that boy. What is implicated here, in other words, is Orlando's homosexual desire, repressed by Elizabethan society. Later on, however, the character finds out that actually the person is not a man, and the seductiveness that came from that person before knowing her to be a woman possesses Orlando in such a way that he forgets about his engagement. In other words, Orlando considers "all embraces" as "out of question" were the person of the same sex as he; notice, however, that the fact that he is committed to someone else does not interfere in the flirting when he knows the person is of another sex.

Later in the story, when Orlando becomes a woman in terms of genitalia, it can be noticed that his/her attitudes vary between being a man and then a woman. I proceed now discussing these changes in Orlando's moral and beliefs. First, Orlando takes time to think critically about her situation. "[f]or some time, however, she was too well pleased with the change to spoil it by thinking" (99). After she begins to think about it, Orlando's positioning regarding gender changes, as she 
becomes aware of the opinions she used to have before the transformation, and modifies them, as if getting adapted by force to the current reality of her new gender role. When Orlando was younger and a man, he/she had different ideas towards the opposite sex, which would become her own contestations with the sexual transformation:

[s] he remembered how, as a young man, she had insisted that women must be obedient, chaste, scented, and exquisitely appareled. 'Now I shall have to pay in my own person for those desires,' she reflected; 'for women are not (judging by my own short experience of the sex) obedient, chaste, scented, and exquisitely appareled by nature. (110)

In other words, Orlando's experiences in being a woman make her reflect about her previous misunderstanding of gender difference, as a man. This reflection leads Orlando to develop critical awareness of her former ("masculine") identity's assumptions about the female gender. In other words, Orlando's change demonstrates the way genders are seen at the time and how they rely on a history of beliefs and conventions arbitrarily dictated by society-as argued by several scholars, gender roles are constructed culturally. By the same token, then, Orlando changes her opinion not only about women, as just quoted, but also about men: "[a]nd mincing out the words, she was horrified to perceive how low an opinion she was forming of the other sex, the manly, to which it had once been her pride to belong" (113). In short, Orlando lives as a man and a woman, and with the transformation he/she becomes aware of the arbitrary gendering of perspective and subject positions.

Though the shift in gender perspective does not seem as easy for Orlando to undergo as does the shift from male to female sex, the narrator suggests that the character learns, eventually, to adapt her behavior to what would be expected from 
a woman. This can be noticed in the following passage, when a man cries in front of Orlando:

[t]hat men cry as frequently and as unreasonably as women, Orlando knew from her own experience as a man; but she was beginning to be aware that women should be shocked when men display emotion in their presence, and so, shocked she was (127, my italics).

The fact that Orlando notices that women "should be shocked" in this situation indicates once more that Orlando is aware of genders being culturally constructed: it is not natural for women to be shocked in this situation, only they should be shocked for cultural reasons. However, at the same time that the narrator conveys the character's apparent adjustment to her new condition, Orlando also questions this condition and criticizes the limitations of being a woman in Elizabethan noble society: "'[w]hat's the good of being a fine young woman in the prime of life', she asks, 'if I have to pass all my morning watching blue-bottles with an Archduke?'" (128). Here, Orlando is disappointed with the cultural reduction of womanhood to such futile roles as paying and receiving court, whereas she expects more from her current condition.

On this account, I call attention to the intersectionality between gender and class suggested in the passage. As Orlando is now a woman, and participates in a privileged class, there are limitations imposed on her due to the roles assigned to women of the class she is occupying. Thus, she as a woman is discriminated within the class she is taking part into, not because of factors related to ability or intelligence to be responsible for other roles in society, but because solely of her gender. In summary, this intersection between gender and class diminishes a group of people (women) in the dimension of roles in a certain class in society. This reading is crucial in order to show how different grounds of identity relate to each 
other in ways that can be prejudicial.

It is important to observe, also, that Orlando tries to adjust herself to womanly habits, but her behavior and critiques of such habits cause her characterization to be ambiguous. This ambiguity indicates that Orlando's characterization within gender identity is marked by fluidity, i.e., the non-fixity and indeterminacy of gender roles:

[i]f Orlando was a woman, how did she never take more than ten minutes to dress? And were not her clothes chosen rather at random, and sometimes worn rather shabby? And then they would say, still, she has none of the formality of a man, or a man's love of power. She is excessively tender-hearted. She could not endure to see a donkey beaten or a kitten drowned. Yet again, they noted, she detested household matters, was up at dawn and out among the fields in summer before the sun had risen. No farmer knew more about the crops than she did. She could drink with the best and liked games of hazard... Whether, then, Orlando was most man or woman, it is difficult to say. (133)

What I am arguing is that Orlando's behavior as a woman as described above disturbs intelligible conceptions of womanhood, paradoxically developing a new identity/identification, one that is not limited to cultural impositions of dualist thinking. In other words, my point is that Orlando is arguably introducing here new ways of being a woman, ways that up to this presentation were not legible to the culture in which the character is inserted. Therefore, textual analysis here proposes the challenge to fixed notions of sex/gender articulations and other identities, and treats identities as mutable signifiers. Indeed, what takes place is Orlando's presentation of a new possibility of identity, an identity until now not legible within cultural constructs. And for this, the text of Orlando: A Biography, needs to be acknowledged.

On account of the findings drawn from the characterizations of Orlando 
within nation, class, and gender, as well as the intersections and the subtexts discussed before, it is necessary to be critical of Orlando's chances to experience different realities and never lose his/her privileges (such as the convenient possibility of returning to the previous nation and class anytime, a privilege of few), added to the fact that he/she often leaves these experiences behind without engaging politically and struggling for changing hierarchies and forms of discrimination. At the same time, though, it is necessary to celebrate Orlando's awakening regarding gender. As I demonstrated before, Orlando undergoes a significant change in gender perspective, and also incorporates constant questioning and critiquing of gender roles and artificial impositions to each gender, proposing, finally, new perspectives for gender politics.

In conclusion, it is crucial to observe that at the same time that Orlando: $A$ Biography presents a transgressive text-a text that disturbs cultural constructs of gender and creates yet "unintelligible" ways of behaving, for example-it is contradicted by a non-transgressive and normatizing subtext, whenever the narrative suggests imperialism. In other words, on the surface the novel challenges ideological and cultural constructs, and criticizes and disturbs hierarchies that cause asymmetries and forms of violence and oppression. However, in the subtext, as indicated several times, the novel actually reinforces such hierarchies and the notion of superiority and inferiority between people in different and intersectional aspects.

\section{Notes}

[1] Brennan's notion that nation is forged, artificial, and imaginarily constructed derives from Benedict Anderson's major argument in Imagined Communities: Reflections on the Origin and Spread of Nationalism. New York and London: Verso, 1991 [1983].

[2] About the conflation of "nation" and "race," I draw on Henri Yu's essay "How Tiger Woods Lost His Stripes: Post-Nationalist American Studies as a History of Race, 
Migration, and the Commodification of Culture." Yu explains that racial type, geographical location, and nationality became understood as correlated since the nineteenth century, and such an arbitrary "mystic tie" (228) has been useful in the understanding of societies and peoples, but risks missing specificities involving these peoples and races. $\mathrm{Yu}$ is therefore critical of the conflation between "nation" and "race," for it constructs, naturalizes, and perpetuates hierarchies.

[3] What Gilbert and Gubar claim, further, is that "to attempt the pen," that is, to write literature, is a way of empowering the self, and since women have been denied the pen in patriarchal Western culture, they have been marginalized and have also been misrepresented by the writings of men. Another consequence, of course, is the impossibility of being empowered and "fighting" (as in a battle) for their interests.

\section{Works Cited}

BRENNAN, Timothy. "The National Longing for Form." Nation and Narration. Ed. Homi K. Bhabha. London: Routledge, 1990: 44-70.

BUTLER, Judith. Gender Trouble: Feminism and the Subversion of Identity. London: Routledge, 1990.

CRENSHAW, Kimberlé Williams. "Mapping the Margins: Intersectionality, Identity Politics, and Violence Against Women of Color." The Public Nature of Private Violence. Eds. Martha Albertson Fineman and Rixanne Mykitiuk. New York: Routledge, 1994. 20 September 2006.

<http://www.hsph.harvard.edu/Organizations/healthnet/WoC/feminisms/cre nshaw.html>

EYRE, A. G. An Outline History of England. London: Longman Group Ltd., 1971.

GILBERT, Sandra, and GUBAR, Susan. The Madwoman in the Attic: the Woman Writer and the Nineteenth Century Literary Imagination. New Haven and London: Yale University Press, 1984.

HIRSCH, E. D., KETT, Joseph F., and TREFIL, James. (eds.). "Class." The New Dictionary of Cultural Literacy. Third Edition. 2002. 20 September 2006. <http://www.bartleby.com/59/17/class.html>

KAVANAGH, James H. "Ideology." Critical Terms for Literary Study. Eds. Frank Lentricchia and Thomas McLaughlin. Chicago and London: The University of Chicago Press, 1990.

LIU, Lydia. "The Female Body and Nationalist Discourse: The Field of Life and Death Revisited." Scattered Hegemonies - Postmodernity and Transnational Feminist Practices. Eds. Inderpal Grewal and Caren Kaplan. Minneapolis and London: University of Minnesota Press, 1994: 37-62.

ROBERTS, Clayton, and ROBERTS, David. A History of England: Prehistory to 1714. Volume 1. New Jersey: Prentice-Hall, Inc., 1991 ( $3^{\text {rd }}$ ed.). 
SINFIELD, Alan. The Wilde Century: Effeminacy, Oscar Wilde and the Queer Moment. New York: Cassell, 1994.

SOLLORS, Werner. "Ethnicity." Critical Terms for Literary Study. Eds. Frank Lentricchia and Thomas McLaughlin. Chicago and London: The University of Chicago Press, 1990.

WOOLF, Virginia. Orlando: A Biography. London: Penguin Books, 1993 [1928].

YU, Henri. "How Tiger Woods Lost His Stripes: Post-Nationalist American Studies as a History of Race, Migration, and the Commodification of Culture." PostNationalist American Studies. Ed. John C. Rowe. Berkeley and Los Angeles: University of California Press, 2000: 223-244. 